\title{
Novel Method for Constructing a Large-Scale Design Space in Lubrication Process by Using Bayesian Estimation Based on the Reliability of a Scale-Up Rule
}

\author{
Jin Maeda, ${ }^{* a}$ Tatsuya Suzuki, ${ }^{a}$ and Kozo Takayama ${ }^{b}$ \\ ${ }^{a}$ Formulation Technology Research Laboratories, Daiichi Sankyo Co., Ltd.; 1-12-1 Shinomiya, Hiratsuka, Kanagawa \\ 254-0014, Japan: and ${ }^{b}$ Department of Pharmaceutics, Hoshi University; 2-4-41 Ebara, Shinagawa-ku, Tokyo 142- \\ 8501, Japan. Received April 15, 2012; accepted June 15, 2012
}

A reliable large-scale design space was constructed by integrating the reliability of a scale-up rule into the Bayesian estimation without enforcing a large-scale design of experiments (DoE). A small-scale DoE was conducted using various Froude numbers $\left(X_{1}\right)$ and blending times $\left(X_{2}\right)$ in the lubricant blending process for theophylline tablets. The response surfaces, design space, and their reliability of the compression rate of the powder mixture $\left(Y_{1}\right)$, tablet hardness $\left(Y_{2}\right)$, and dissolution rate $\left(Y_{3}\right)$ on a small scale were calculated using multivariate spline interpolation, a bootstrap resampling technique, and self-organizing map clustering. A constant Froude number was applied as a scale-up rule. Experiments were conducted at four different small scales with the same Froude number and blending time in order to determine the discrepancies in the response variables between the scales so as to indicate the reliability of the scale-up rule. Three experiments under an optimal condition and two experiments under other conditions were performed on a large scale. The response surfaces on the small scale were corrected to those on the large scale by Bayesian estimation using the large-scale results and the reliability of the scale-up rule. Large-scale experiments performed under three additional sets of conditions showed that the corrected design space was more reliable than the small-scale design space even when there was some discrepancy in the pharmaceutical quality between the manufacturing scales. This approach is useful for setting up a design space in pharmaceutical development when a DoE cannot be performed at a commercial large manufacturing scale.

Key words quality by design; design of experiments; multivariate regression; modeling

The international conference on harmonization $(\mathrm{ICH})^{1)}$ outlined quality by design $(\mathrm{QbD})$ as a systematic approach to development that begins with predefined objectives and emphasizes product and process understanding and process control, based on sound science and quality risk management. The QbD principle implies that pharmaceutical quality should not be tested using day-to-day release testing but should be elaborated by design in advance. One of the most significant approaches in the QbD concept is the establishment of a design space based on a multidimensional combination of input formulation parameters, process parameters, or material attributes that provide assurance of quality attributes. ${ }^{2)}$

Design of experiments (DoE) studies $^{3,4}$ have been used effectively to construct design spaces. DoE is a useful method for systematic understanding of the relationship between input parameters and output quality attributes. A typical design space is established as a superposition of the response surfaces for each quality attribute generated by the response surface method (RSM) using the DoE results. ${ }^{5-11)}$ The RSM includes statistical analyses such as multiple linear regression analysis $^{12)}$ and artificial neural networks. ${ }^{13)}$ Takayama et al. developed a novel RSM that incorporates multivariate spline interpolation, known as RSM-S. ${ }^{14,15)}$ RSM-S is an effective tool for obtaining reliable response surfaces of nonlinear phenomena and calculating optimal solutions. A bootstrap resampling technique and self-organizing map (SOM) clustering have been reported to qualify the reliabilities of optimal solutions ${ }^{16-18)}$ and response surfaces. ${ }^{19)}$

In order to construct a reliable design space for commercial-scale manufacturing of a drug product, a number of

The authors declare no conflict of interest. experiments based on the DoE principles should be conducted on a commercial scale. However, it is practically difficult to perform these experiments because of the high costs involved. Therefore, DoE studies on establishing a design space have often been conducted on a manufacturing scale smaller than the commercial scale based on scale-up rules. Scale-up rules that are often widely used include a constant Froude number ${ }^{20)}$ for blending and a constant Froude number ${ }^{21)}$ or power consumption of the impeller motor ${ }^{22}$ for wet high-shear granulation. However, the scale-up of high-shear granulation conducted by Ogawa et al. indicated that a constant peripheral velocity resulted in a discrepancy in the design spaces between manufacturing scales. ${ }^{12)}$ This finding indicated that, at present, there is no universal and absolute scale-up rule that can be applied to all pharmaceuticals. Meanwhile, the ICH Quality Implementation Working Group has suggested that the impact of the manufacturing scale on the DoE results should be clarified and reduced. ${ }^{23}$ ) Therefore, if the scale-up rule used is found to contain errors after a further scale-up, the design space constructed on a pilot scale cannot be applied to commercial manufacturing.

Bayesian estimation based on posterior probability distribution can be used to estimate the probability of uncertain phenomena. The posterior probability distribution can be calculated from the prior probability distribution and a few additional data using the Bayes theorem. Bayesian estimation has been applied to the information technology industry, and to economics and population pharmacokinetics in the pharmaceutical sciences. Peterson reported the usability of Bayesian estimation by calculating the probability that the quality attributes would meet specifications and by constructing a credible design space. ${ }^{24)}$ 


\begin{tabular}{|c|c|c|c|}
\hline $\begin{array}{c}\text { Manufacturing } \\
\text { scale }\end{array}$ & $\begin{array}{l}\text { Experimental } \\
\text { condition }\end{array}$ & \multicolumn{2}{|c|}{ Bayesian estimation } \\
\hline \multirow[t]{2}{*}{$1 / 1(3 \mathrm{~kg})$} & & $\begin{array}{c}\text { Improved } \\
\mathrm{RS}_{\text {large }}{ }^{\mathrm{a}} \\
\uparrow\end{array}$ & $\begin{array}{c}\text { Previous } \\
\mathrm{RS}_{\text {large }}{ }^{\circ} \\
\uparrow\end{array}$ \\
\hline & & \multicolumn{2}{|c|}{ Likelihood $\left(\mu_{1}, \sigma_{1}\right)$} \\
\hline $1 / 5(600 \mathrm{~g})$ & iी & & \\
\hline \multirow{3}{*}{$1 / 10(300 \mathrm{~g})$} & & $\begin{array}{c}\text { Prior probability } \\
\left(\sigma_{\text {scale }}\right)\end{array}$ & \\
\hline & & \multicolumn{2}{|c|}{ Prior probability $\left(\mu_{0}, \sigma_{\text {model }}\right)$} \\
\hline & $\mathrm{DoE}$ & \multicolumn{2}{|c|}{$\mathrm{RS}_{\text {small }}$} \\
\hline $1 / 20(150 \mathrm{~g})$ & $\dot{\phi}$ & & \\
\hline $1 / 67(45 \mathrm{~g})$ & $\dot{\theta}$ & & \\
\hline
\end{tabular}

Fig. 1. Construction Process for Commercial-Scale Response Surfaces Using Bayesian Estimation

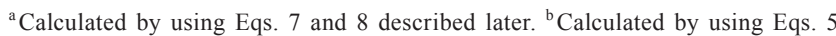
and 6 described later.

We previously reported that a reliable large-scale design space was constructed using a Bayesian estimation method with a small-scale DoE and five batches of large-scale manufacturing data without enforcing a large-scale DoE. ${ }^{25}$ The large-scale design space was more reliable than the small-scale one, despite the small discrepancy in the pharmaceutical quality between the two manufacturing scales. However, we believed that a more reliable design space could be constructed if a precision of the scale-up rule was predicted in advance and the large-scale data was emphasized more than the small-scale design space in Bayesian estimation, when the scale-up rule was less reliable.

In this study, we developed a more useful method for constructing a more reliable large-scale design space by integrating the reliability of the scale-up rule into the Bayesian estimation method. The reliability of the scale-up rule was estimated as the deviation of the quality attributes when the product was manufactured on various small scales. The lubrication process used for theophylline tablet manufacturing was chosen as a model experimental system for the design space construction. We also validated the large-scale design space estimated by the improved method and compared it with the small-scale design space and the previously-reported large-scale design space. ${ }^{25}$

\section{Experimental}

The setup process for the plant-scale response surfaces utilizing Bayesian estimation is summarized in Fig. 1. We attempted to construct a Bayesian design space for
Table 1. Components and Composition of Theophylline Tablets

\begin{tabular}{lc}
\hline \hline \multicolumn{1}{c}{ Components } & Quantity (mg/tablet) \\
\hline Theophylline & 100 \\
Lactose monohydrate & 66.5 \\
Cornstarch & 28.5 \\
Microcrystalline cellulose & 50 \\
Magnesium stearate & 5 \\
Total & 250 \\
\hline
\end{tabular}

the lubrication process of theophylline tablets applied to a large scale $(3 \mathrm{~kg})$ using the design space constructed from a small-scale $(0.3 \mathrm{~kg})$ DoE study, three-batch experiments at various small scales, and five-batch experiments on the large scale.

Materials Theophylline (Hachidai Pharmaceutical Co., Japan), lactose monohydrate (Dilactose $\mathrm{S}^{\circledR}$, Freund Corporation, Japan), cornstarch (Nihon Shokuhin Kako Co., Japan), microcrystalline cellulose (Ceolus ${ }^{\circledR}$ PH-101, Asahi Kasei Chemicals Co., Japan), and magnesium stearate (Mallinckrodt, Inc., Doral, Florida, U.S.A.) were used in all the experiments.

Scale-Up Rule A constant Froude number was applied as the scale-up rule. A Froude number ${ }^{20)}$ is a scale-independent variable defined as:

$$
F r=r(\pi n)^{2} / 900 g
$$

where $r(\mathrm{~m})$ is the rotating radius of a blender, $n(\mathrm{rpm})$ is the rotating speed, and $g\left(\mathrm{~m} / \mathrm{s}^{2}\right)$ is the acceleration of gravity.

Preparation of the Theophylline Tablets The theophylline tablets used in this study were produced using the direct compression method with the formulation shown in Table 1. V-shaped blenders with volumes of $150 \mathrm{~mL}, 500 \mathrm{~mL}, 1 \mathrm{~L}, 2 \mathrm{~L}$ (Type S-5, Tsutsui Scientific Instruments Co., Japan), and $10 \mathrm{~L}$ (TCV-30, Tokuju Co., Japan) were used to prepare mixtures for tableting. The 10-L scale was regarded as the large scale, whereas the other volumes were regarded as small scales. The specifications and operational conditions used for the blenders are summarized in Table 2.

All ingredients, except magnesium stearate, were blended in the V-shaped blenders at a Froude number of 0.25 (45 rpm in the $1-\mathrm{L}$ blender and $32 \mathrm{rpm}$ in the $10-\mathrm{L}$ blender) for $15 \mathrm{~min}$. The blended mixture was sieved in a screening mill (Quadro Comil, Powrex Corporation, Japan) with a screen size of $0.991 \mathrm{~mm}$ and an impeller rotating speed of $300 \mathrm{rpm}$. After adding the magnesium stearate, the mixture was further blended to obtain the final blend in the V-shaped blenders at different predetermined rotation speeds and blending times. The final blend was compressed with $8.5-\mathrm{mm}$ round punches and biconvex faces at $250-\mathrm{mg}$ weight and $7-\mathrm{kN}$ compression

Table 2. Specifications and Operational Conditions of the V-Shaped Blenders

\begin{tabular}{|c|c|c|c|c|c|}
\hline Blender type & $\mathrm{V}-150 \mathrm{~mL}$ & $\mathrm{~V}-500 \mathrm{~mL}$ & $\mathrm{~V}-1 \mathrm{~L}$ & $\mathrm{~V}-2 \mathrm{~L}$ & $\mathrm{~V}-10 \mathrm{~L}$ \\
\hline Blender volume (L) & 0.15 & 0.5 & 1 & 2 & 10 \\
\hline Total charge of mass $(\mathrm{kg})$ & 0.045 & 0.15 & 0.3 & 0.6 & 3 \\
\hline$X_{1}:$ Froude number & 0.25 & 0.25 & $0.10-0.40$ & 0.25 & $0.10-0.40$ \\
\hline Rotating radius (m) & 0.065 & 0.09 & 0.11 & 0.155 & 0.22 \\
\hline Rotating speed (rpm) & 59 & 50 & $29-57$ & 38 & $20-40$ \\
\hline$X_{2}$ : Blending time (min) & 30 & 30 & $2-58$ & 30 & $2-58$ \\
\hline
\end{tabular}


force per tablet using a 24-station rotating tableting machine (Correct 24, Kikusui Co., Japan).

Small-Scale DoE The Froude number $\left(X_{1}\right)$ and blending time $\left(X_{2}\right)$ were selected as the input variables. A total of nine experiments were performed using the V-1 L blender to obtain the response surfaces of each response variable according to the two-factor three-level $\left(3^{2}\right)$ experimental design (Table 3 ).

Evaluation of Powder and Tablets Properties The compression rate of the powder mixture $\left(Y_{1}\right)$, tablet hardness $\left(Y_{2}\right)$, and dissolution rate at $30 \mathrm{~min}\left(Y_{3}\right)$ were selected as the response variables.

The compression rate $(C R)^{26)}$ is an indicator of powder flowability, which is defined as follows:

$$
C R(\%)=\left(\rho_{\mathrm{T}}-\rho_{\mathrm{L}}\right) / \rho_{\mathrm{T}} \times 100
$$

where $\rho_{\mathrm{T}}$ and $\rho_{\mathrm{L}}$ indicate the tapped and loose densities of the powder $\left(\mathrm{kg} / \mathrm{m}^{3}\right)$, respectively. The tapped and loose densities of the mixture for tableting were measured using tap density equipment (SZ-02, Rinkan Co., Japan).

The tablet hardness was measured using a tablet hardness tester (Tablet tester Pharmatest WHT, Pharma Test Apparatebau, Germany). Dissolution testing was performed using a 50 -rpm paddle and $900 \mathrm{~mL}$ of water at $37^{\circ} \mathrm{C}$. The sample solution was assayed using an automated flow-through UV spectrophotometric method at $253 \mathrm{~nm}$ with a 10 -mm-long cell (Automated dissolution apparatus, Toyama Sangyo Co. and Shimadzu Co., Japan).

Construction of the Response Surfaces and Design Space on the Small Scale and Calculation of the Simultaneously Optimal Condition RSM-S was carried out to calculate the response surfaces and the simultaneously optimal solution on a small scale using dataNESIA ${ }^{\mathrm{TM}}$ version 3.0 (Yamatake Corp., Tokyo, Japan). The criteria for the quality attributes in this case study were set as follows: $Y_{1}=0.320$ (upper limit), $Y_{2}=30 \mathrm{~N}$ (lower limit), and $Y_{3}=75 \%$ (lower limit). The acceptance areas for each quality attribute were superposed to determine a design space. The standard deviation of the response surfaces, which represented the reliability of the models, was evaluated with the bootstrap resampling technique and SOM clustering using dataNESIA ${ }^{\mathrm{TM}}$ and Viscovery ${ }^{\circledR}$ (Eudaptics Software Gmbh, Austria), respectively, according to the previously reported methods. ${ }^{17,18)}$ Bootstrap resampling was performed 200 times.

Experimental Design for Estimating the Reliability of the Scale-Up Rule Experiments were conducted at three different small scales, with the same Froude number and blending time as used for the central condition of the DoE, in order to determine the discrepancies in the response variables between the scales and to estimate the reliability of the scale-up rule (Table 4).

Theory of Bayesian Estimation Bayesian estimation is a methodology used to construct a posterior probability distribution for an uncertain phenomenon. The posterior probability distribution is computed with the Bayes theorem considering an assumed prior probability and likelihood estimated from newly observed data.

When the prior probability and likelihood are expressed as normal distributions, the posterior probability is also distributed normally. ${ }^{27)}$ The average and standard deviation of the posterior probability distribution are expressed as follows:

Table 3. Input Parameters and Output Properties of Small-Scale DoE

\begin{tabular}{|c|c|c|c|c|c|}
\hline \multicolumn{3}{|c|}{ Input process parameter } & \multicolumn{3}{|c|}{ Output quality attribute } \\
\hline$X_{1}$ & & $X_{2}$ & $Y_{1}$ & $Y_{2}$ & $Y_{3}$ \\
\hline Froude number & $\begin{array}{l}\text { Rotation speed in } \mathrm{V}-1 \mathrm{~L} \\
(\mathrm{rpm})\end{array}$ & $\begin{array}{l}\text { Blending time } \\
(\mathrm{min})\end{array}$ & Compression rate & $\begin{array}{l}\text { Hardness } \\
\text { (N) }\end{array}$ & $\begin{array}{c}\text { Dissolution rate at } 30 \mathrm{~min} \\
(\%)\end{array}$ \\
\hline 0.10 & 29 & 2 & 0.340 & 71.7 & 90.2 \\
\hline 0.10 & 29 & 30 & 0.320 & 51.6 & 85.0 \\
\hline 0.10 & 29 & 58 & 0.289 & 37.8 & 81.1 \\
\hline 0.25 & 45 & 2 & 0.345 & 67.3 & 89.1 \\
\hline 0.25 & 45 & 30 & 0.286 & 39.4 & 81.1 \\
\hline 0.25 & 45 & 58 & 0.242 & 24.2 & 75.6 \\
\hline 0.40 & 57 & 2 & 0.339 & 60.3 & 86.3 \\
\hline 0.40 & 57 & 30 & 0.255 & 31.0 & 77.4 \\
\hline 0.40 & 57 & 58 & 0.240 & 21.9 & 67.8 \\
\hline
\end{tabular}

Table 4. Results of Experiments Conducted on Various Small-Scales

\begin{tabular}{|c|c|c|c|c|c|c|}
\hline \multicolumn{4}{|c|}{ Input process parameter } & \multicolumn{3}{|c|}{ Output quality attribute } \\
\hline & $X_{1}$ & & $X_{2}$ & $Y_{1}$ & $Y_{2}$ & $Y_{3}$ \\
\hline Blender type & Froude number & $\begin{array}{l}\text { Rotation speed } \\
(\mathrm{rpm})\end{array}$ & $\begin{array}{l}\text { Blending time } \\
(\min )\end{array}$ & Compression rate & $\begin{array}{l}\text { Hardness } \\
\text { (N) }\end{array}$ & $\begin{array}{c}\text { Dissolution rate at } \\
30 \mathrm{~min}(\%)\end{array}$ \\
\hline $\mathrm{V}-150 \mathrm{~mL}$ & 0.25 & 60 & 30 & 0.277 & 37.5 & 80.4 \\
\hline $\mathrm{V}-500 \mathrm{~mL}$ & 0.25 & 51 & 30 & 0.297 & 41.6 & 82.0 \\
\hline $\mathrm{V}-1 \mathrm{~L}$ & 0.25 & 45 & 30 & 0.286 & 39.4 & 81.1 \\
\hline $\mathrm{V}-2 \mathrm{~L}$ & 0.25 & 39 & 30 & 0.290 & 31.2 & 73.5 \\
\hline \multicolumn{4}{|c|}{ Standard deviation of quality attributes between manufacturing scales $\left(\sigma_{\text {scale }}\right)$} & 0.008 & 4.5 & 3.9 \\
\hline
\end{tabular}




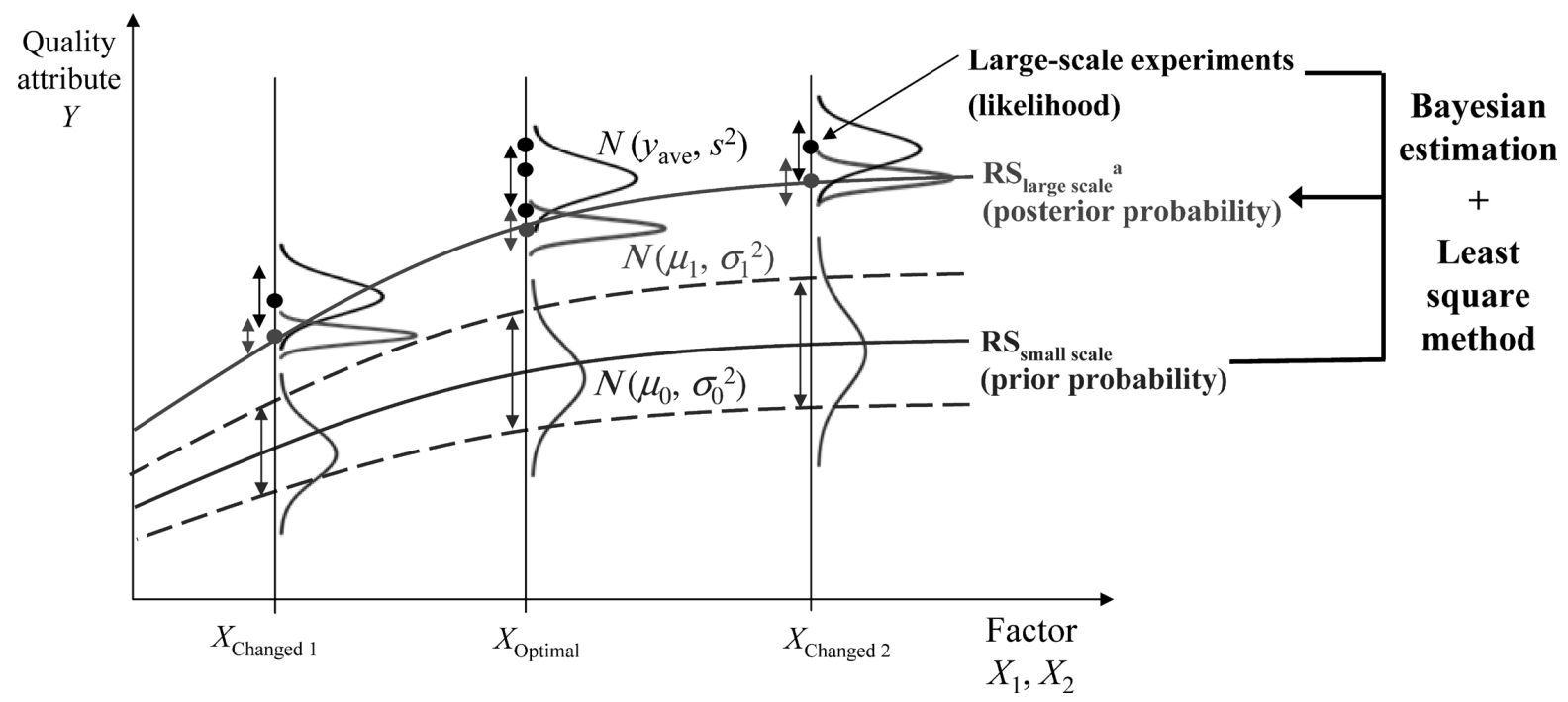

Fig. 2. The Bayesian Estimation Process

${ }^{a}$ RS: response surface. $X_{\text {Optimal }}$ represents the simultaneously optimal condition and $X_{\text {Changed } 1}$ and $X_{\text {Changed } 2}$ represent the changed large-scale experimental conditions for the Bayesian estimation.

$$
\begin{gathered}
\mu_{1}=\frac{\frac{1}{\sigma_{0}^{2}} \mu_{0}+\frac{n}{s^{2}} y_{\text {ave }}}{\frac{1}{\sigma_{0}^{2}}+\frac{n}{s^{2}}} \\
\frac{1}{\sigma_{1}^{2}}=\frac{1}{\sigma_{0}^{2}}+\frac{n}{s^{2}}
\end{gathered}
$$

where $\mu_{1}$ and $\sigma_{1}$ are the average and standard deviation of the posterior probability distribution, $\mu_{0}$ and $\sigma_{0}$ are the average and standard deviation of the prior probability distribution, and $y_{\text {ave }}$ and $s$ are the average and standard deviation of the likelihood distribution, respectively. The average of the posterior probability $\left(\mu_{1}\right)$ is the internally dividing value of the averages of the prior probability and likelihood with the standard deviation of the two values. The variance of the posterior probability $\left(\sigma_{1}^{2}\right)$ is the harmonic average of the variance of the prior probability and likelihood, which means that the reliability of the posterior probability is higher than that of the prior probability and likelihood.

Construction of Response Surfaces and Design Space on a Large-Scale Using Bayesian Estimation The Bayesian estimation process is shown in Fig. 2. The value of each quality attribute expressed by the response surfaces in a certain condition was regarded as the average of the prior probability.

In our previous report ${ }^{25)}$ only the standard deviation of the response surfaces calculated by the bootstrap resampling was considered as the standard deviation of the prior probability:

$$
\begin{gathered}
\mu_{1}=\frac{\frac{1}{\sigma_{\text {model }}^{2}} \mu_{0}+\frac{n}{s^{2}} y_{\text {ave }}}{\frac{1}{\sigma_{\text {model }}^{2}}+\frac{n}{s^{2}}} \\
\frac{1}{\sigma_{1}^{2}}=\frac{1}{\sigma_{\text {model }}^{2}}+\frac{n}{s^{2}}
\end{gathered}
$$

where $\sigma_{\text {model }}$ is the standard deviation of the response surfaces calculated by the bootstrap resampling method. Then, we improved the method to reflect the reliability of the scale-up rule as follows:

$$
\begin{gathered}
\mu_{1}=\frac{\frac{1}{\sigma_{\text {model }}^{2}+\sigma_{\text {scale }}^{2}} \mu_{0}+\frac{n}{s^{2}} y_{\text {ave }}}{\frac{1}{\sigma_{\text {model }}^{2}+\sigma_{\text {scale }}^{2}}+\frac{n}{s^{2}}} \\
\frac{1}{\sigma_{1}^{2}}=\frac{1}{\sigma_{\text {model }}^{2}+\sigma_{\text {scale }}^{2}}+\frac{n}{s^{2}}
\end{gathered}
$$

where $\sigma_{\text {scale }}$ is the standard deviation of the quality attributes when manufacturing was conducted at various small scales according to the scale-up rule. In order to calculate the likelihood, five batches of large-scale manufacturing were conducted. Three batches were performed under the simultaneously optimal condition to calculate standard deviation of the likelihood. For the other batches, two different conditions were selected for performing the Bayesian estimation. Application of Bayesian estimation outside of the region of three large-scale manufacturing conditions can lead to poor prediction accuracy. Therefore, the two conditions should be far from the optimal condition and lead to the production of poor-quality tablets in order to correct the whole response surfaces across the edges of the design space. A small number of large-scale experiments could increase the predictive error of the estimated response surface. Therefore, the adequacy of using five large-scale experiments under three conditions was checked by the validation experiments described further.

The standard deviation of the likelihood was determined using the following equation, which can estimate the standard deviation from the range of the obtained data ${ }^{28)}$.

$$
s=0.591 \times\left(\max \left(Y_{\mathrm{i}}, Y_{\mathrm{ii}}, Y_{\mathrm{iii}}\right)-\min \left(Y_{\mathrm{i}}, Y_{\mathrm{ii}}, Y_{\mathrm{iii}}\right)\right)
$$

where $Y_{\mathrm{i}}, Y_{\mathrm{ii}}$ and $Y_{\mathrm{iii}}$ are the quality attributes of the three large-scale experimental batches under the optimal condition. We considered that the calculated standard deviation was constant under any manufacturing condition. If the assumption is wrong, the predictive error of the estimated response surface could increase. Therefore, the validity of the assumption was also verified by the after-mentioned validation experiments. 
(a)

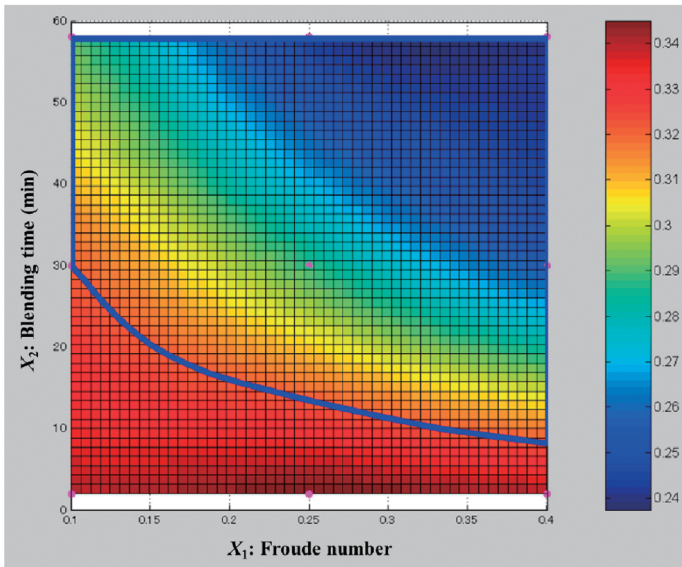

(b)

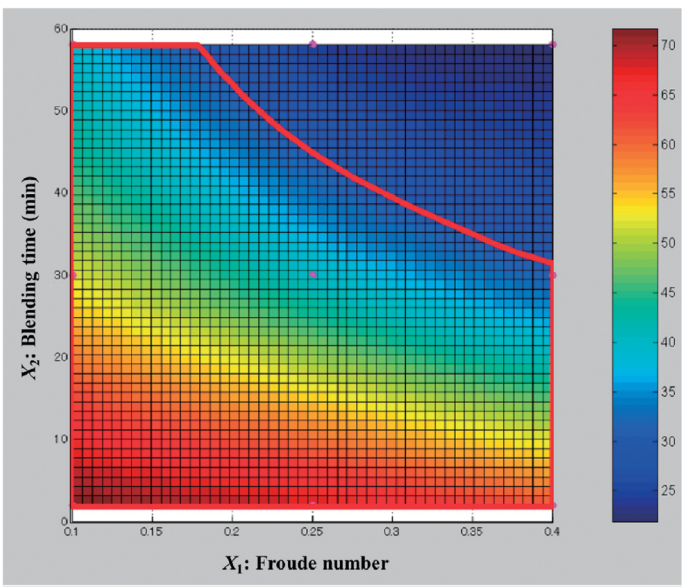

(c)

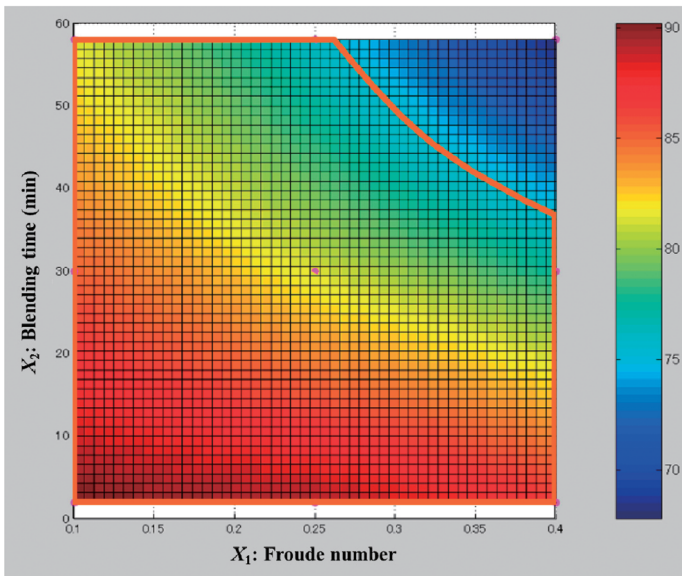

Fig. 3. Response Surfaces for Quality Attributes on the Small Scale

(a) Compression rate of powder mixture $\left(Y_{1}\right)$, (b) tablet hardness $\left(Y_{2}\right)$, and (c) dissolution rate at $30 \mathrm{~min}\left(Y_{3}\right)$. The solid line represents the edge of the acceptance area for each quality attribute.

Based on the information of the prior probability and likelihood, the Bayesian estimate for the three input process parameters was calculated using Eqs. 7 and 8 .

The small-scale response surfaces were corrected to generate the large-scale response surfaces using the following equation:

$$
F\left(X_{1}, X_{2}\right)=a \times f\left(X_{1}, X_{2}\right)+b
$$

where $F\left(X_{1}, X_{2}\right)$ and $f\left(X_{1}, X_{2}\right)$ are functions expressing the

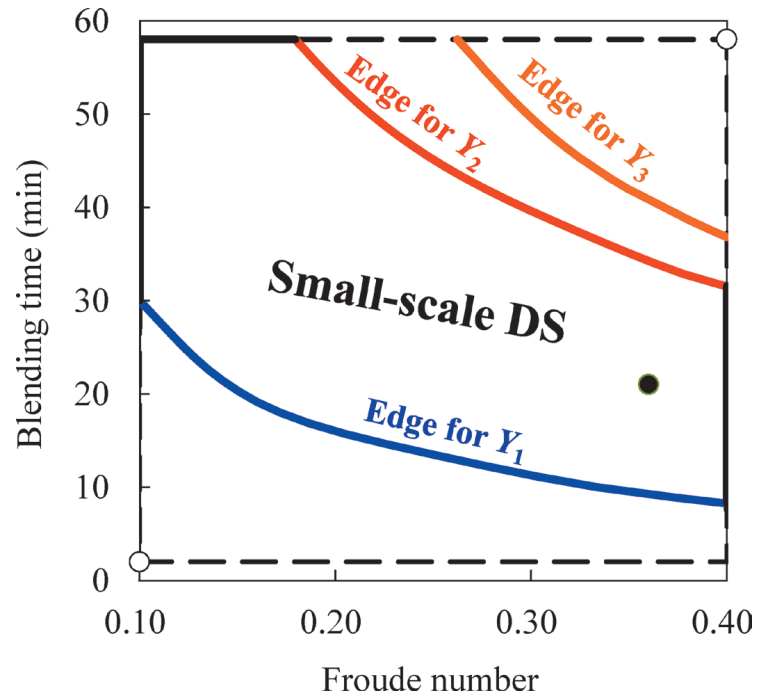

Fig. 4. Design Space on the Small Scale

The solid line represents the edge of the small-scale design space. The symbol (O) represents the simultaneously optimal condition, and $(\bigcirc)$ represents the changed large-scale experimental conditions for the Bayesian estimation.

large-scale and small-scale response surfaces, respectively, and $a$ and $b$ are correction coefficients. Because the small-scale response surfaces were nonlinear curves, the corrected response surfaces were also nonlinear. The large-scale response surfaces should pass through three points of the Bayesian estimate. Therefore, the correction coefficients were determined by the least square method between the Bayesian estimates (objective variable) and the quality attributes estimated from the small-scale response surface (explanatory variable) for the three conditions. The least square method was performed using the statistical software JMP ${ }^{\circledR} 8$ (SAS Institute Inc., NC, U.S.A.). The large-scale response surfaces were estimated by correcting the whole small-scale response surfaces using the calculated correction coefficients. The area where all quality attributes met the acceptance criteria in the large-scale manufacturing was superposed to establish a design space.

Validation of the Response Surfaces Experiments to validate the estimated response surfaces were conducted on a large scale under three different conditions, which were different from the three large-scale experimental conditions used for the Bayesian estimation. These were located on the edge of the large-scale design space. The root mean square error of prediction (RMSEP) and bias were used as the indices for evaluating the accuracy of the response surfaces. RMSEP and bias were calculated using the following equations:

$$
\begin{aligned}
R M S E P & =\sqrt{\frac{\sum_{k=1}^{n}\left(Y_{\text {actual }}-Y_{\text {predicted }}\right)^{2}}{n}} \\
\text { bias } & =\frac{\sum_{k=1}^{n}\left(Y_{\text {actual }}-Y_{\text {predicted }}\right)}{n}
\end{aligned}
$$

where $n$ is the number of validation experiments. RMSEP is an estimate of the typical difference between the predicted and actual values and bias is the average difference. The prediction accuracy of the models improved with decreasing 
values of RMSEP and bias. Moreover, good validation results indicated that the number of large-scale experiments was adequate.

\section{Results and Discussion}

Construction of Response Surfaces and Design Space on a Small Scale and Calculation of a Simultaneously Optimal Solution The DoE design and the results for the compression rate of the powder mixture $\left(Y_{1}\right)$, tablet hardness $\left(Y_{2}\right)$, and dissolution rate at $30 \mathrm{~min}\left(Y_{3}\right)$ on the small scale are listed in Table 3 . All of the output quality attributes varied in response to the changes in the input blending conditions. The response surfaces of the output quality attributes were generated by RSM-S as functions of two causal factors: the Froude number $\left(X_{1}\right)$ and the blending time $\left(X_{2}\right)$ (Fig. 3). The response surface indicated that an increase in the Froude number or blending time improved the flowability of the powder mixture, as shown by the decrease in the compression rate. Thus, the tabletability would also improve. The area with a smaller Froude number and blending time did not meet the upper limit of the compression rate $(0.320)$. Increasing the blending time resulted in good lubricant uniformity and reduced the tablet hardness and dissolution rate. The hardness met the lower limit $(30 \mathrm{~N})$ within the acceptance range. The dissolution rate met the lower limit (75\%) in most of the experimental area. A design space on a small scale was determined as the common region of the three acceptance areas (Fig. 4). Furthermore, the simultaneously optimal solution was calculated to be an $X_{1}$ of 0.36 and an $X_{2}$ of 21 min by using dataNESIA ${ }^{\circledR}$.

Estimation of the Reliability of the Scale-Up Rule The quality attributes of the theophylline tablets manufactured on the different small scales according to the scale-up rule are listed in Table 4. The standard deviation of the compression rate was small, which meant that powder flowability did not differ between the manufacturing scales as long as the Froude number was kept constant. Furthermore, standard deviations of the hardness and dissolution rate were large. These results indicated that the abovementioned quality attributes did not follow the scale-up rule.

Construction of Response Surfaces and Design Space on a Large Scale by Bayesian Estimation In addition to the optimal condition $\left(X_{\text {optimal }}\right)$ estimated in the small-scale DoE study, we used two different conditions for the large-scale experiments for Bayesian estimation at points $X_{\text {changed } 1}(0.10$, $2 \mathrm{~min})$ and $X_{\text {changed } 2}(0.40,58 \mathrm{~min})$ in the $X_{1}-X_{2}$ coordinates (Fig. 4). The points $X_{\text {changed } 1}$ and $X_{\text {changed2 }}$ were at the edge of the experimental range and far from the $X_{\text {optimal }}$ point. The condition $X_{\text {changed } 1}$ was considered to lead to poor flowability of the powder mixture, and the condition $X_{\text {changed2 }}$ was considered to produce tablets with a low hardness and dissolution rate. Furthermore, we thought that Bayesian estimations of $X_{\text {optimal }}, X_{\text {changed } 1}$, and $X_{\text {changed } 2}$ made it possible to correct the whole response surfaces across the edges of the design space.

Quality attributes were predicted based on the small-scale

Table 5. Results of the Large-Scale Experiments and Bayesian Estimation

\begin{tabular}{|c|c|c|c|c|}
\hline Large-scale manufacturing condition & & Optimal & Changed 1 & Changed 2 \\
\hline$X_{1}$ Froude number & & 0.36 & 0.10 & 0.40 \\
\hline Rotation speed in V-10L (rpm) & & 38 & 20 & 40 \\
\hline$X_{2}$ Time $(\min )$ & & 21 & 2 & 58 \\
\hline \multicolumn{5}{|l|}{$Y_{1}$ Compression rate } \\
\hline \multirow[t]{3}{*}{ Predicted value from the small-scale $\mathrm{RS}^{a)}$} & Average $\left(\mu_{0}\right)$ & 0.284 & 0.340 & 0.240 \\
\hline & $\mathrm{SD}\left(\sigma_{\text {model }}\right)$ & 0.010 & 0.017 & 0.015 \\
\hline & $\mathrm{SD}\left(\sigma_{\text {scale }}\right)$ & 0.008 & 0.008 & 0.008 \\
\hline \multirow[t]{3}{*}{ Experiment data in the large scale } & Individual & $0.286,0.277,0.270$ & 0.340 & 0.236 \\
\hline & Average $\left(y_{\text {ave }}\right)$ & 0.278 & 0.340 & 0.236 \\
\hline & $\mathrm{SD}(s)$ & 0.009 & & \\
\hline \multirow[t]{2}{*}{ Bayesian estimate $^{b)}$} & Average $\left(\mu_{1}\right)$ & 0.279 & 0.340 & 0.237 \\
\hline & $\mathrm{SD}\left(\sigma_{1}\right)$ & 0.005 & 0.008 & 0.008 \\
\hline \multicolumn{5}{|l|}{$Y_{2}$ Hardness $(\mathrm{N})$} \\
\hline \multirow[t]{3}{*}{ Predicted value from the small-scale $\mathrm{RS}^{a}$} & Average $\left(\mu_{0}\right)$ & 40.9 & 71.7 & 21.9 \\
\hline & $\mathrm{SD}\left(\sigma_{\text {model }}\right)$ & 2.6 & 2.0 & 4.5 \\
\hline & $\operatorname{SD}\left(\sigma_{\text {scale }}\right)$ & 4.5 & 4.5 & 4.5 \\
\hline \multirow[t]{3}{*}{ Experiment data in the large scale } & Individual & $25.1,29.7,27.5$ & 53.8 & 18.7 \\
\hline & Average $\left(y_{\text {ave }}\right)$ & 27.4 & 53.8 & 18.7 \\
\hline & $\mathrm{SD}(s)$ & 2.7 & & \\
\hline \multirow[t]{2}{*}{ Bayesian estimate $^{\mathrm{b}}$} & Average $\left(\mu_{1}\right)$ & 28.6 & 58.0 & 19.2 \\
\hline & $\mathrm{SD}\left(\sigma_{1}\right)$ & 1.5 & 2.4 & 2.5 \\
\hline \multicolumn{5}{|l|}{$Y_{3}$ Dissolution rate at $30 \mathrm{~min}(\%)$} \\
\hline \multirow[t]{3}{*}{ Predicted value from the small-scale $\mathrm{RS}^{a)}$} & Average $\left(\mu_{0}\right)$ & 81.4 & 90.2 & 67.8 \\
\hline & $\mathrm{SD}\left(\sigma_{\text {model }}\right)$ & 0.6 & 1.5 & 1.9 \\
\hline & $\mathrm{SD}\left(\sigma_{\text {scale }}\right)$ & 3.9 & 3.9 & 3.9 \\
\hline \multirow[t]{3}{*}{ Experiment data in the large scale } & Individual & $75.3,75.8,77.2$ & 85.0 & 67.8 \\
\hline & Average $\left(y_{\text {ave }}\right)$ & 76.1 & 85.0 & 67.8 \\
\hline & $\mathrm{SD}(s)$ & 1.1 & & \\
\hline \multirow[t]{2}{*}{ Bayesian estimate ${ }^{b)}$} & Average $\left(\mu_{1}\right)$ & 76.2 & 85.4 & 67.8 \\
\hline & $\mathrm{SD}\left(\sigma_{1}\right)$ & 0.6 & 1.1 & 1.1 \\
\hline
\end{tabular}

a) RS: response surface. $b$ ) Calculated by using Eqs. 7 and 8 . 
(a)

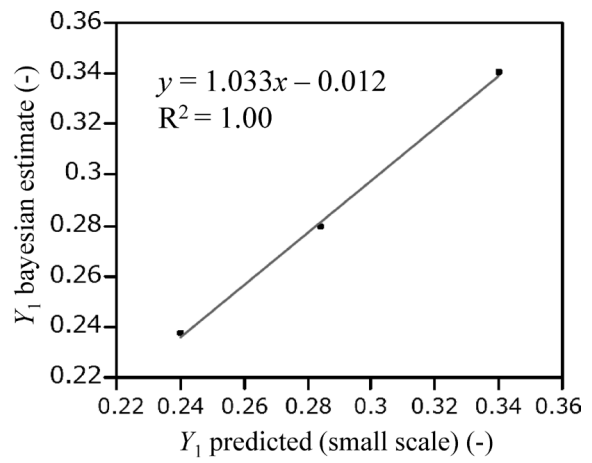

(b)

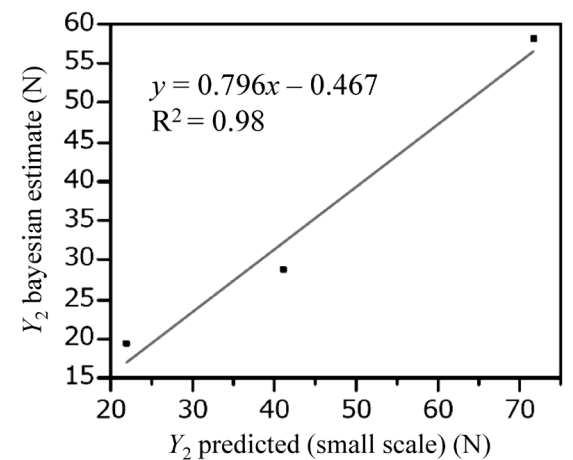

(c)

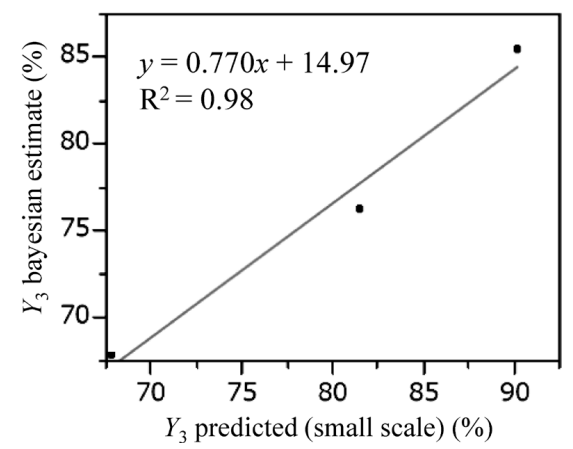

Fig. 5. Results of the Least-Square Approximation

(a) Compression rate of powder mixture $\left(Y_{1}\right)$, (b) tablet hardness $\left(Y_{2}\right)$ and (c) dissolution rate at $30 \mathrm{~min}\left(Y_{3}\right)$.

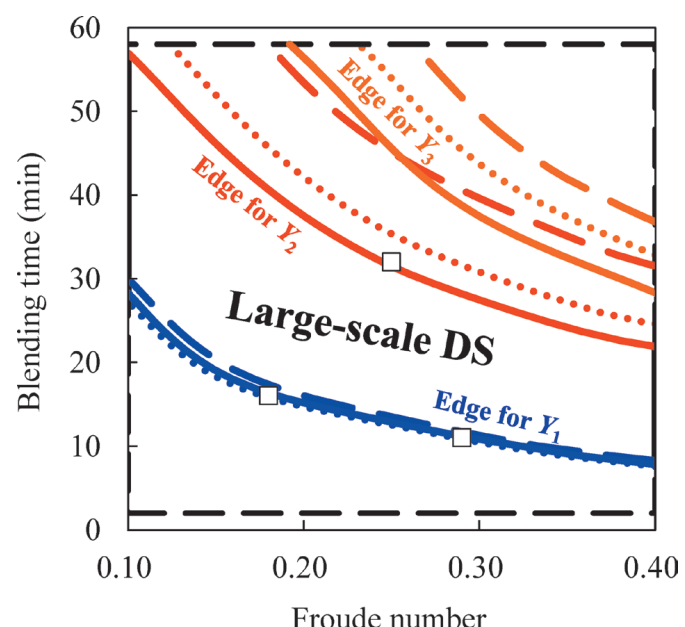

Fig. 7. Design Space on the Large Scale

The dashed line represents the edge of the small-scale acceptance area, the dotted line represents the edge of the previously-reported large-scale acceptance area, and the solid line represents the edge of the improved large-scale acceptance area. The symbol $(\square)$ represents large-scale experimental conditions for validation of the response surfaces. (a)

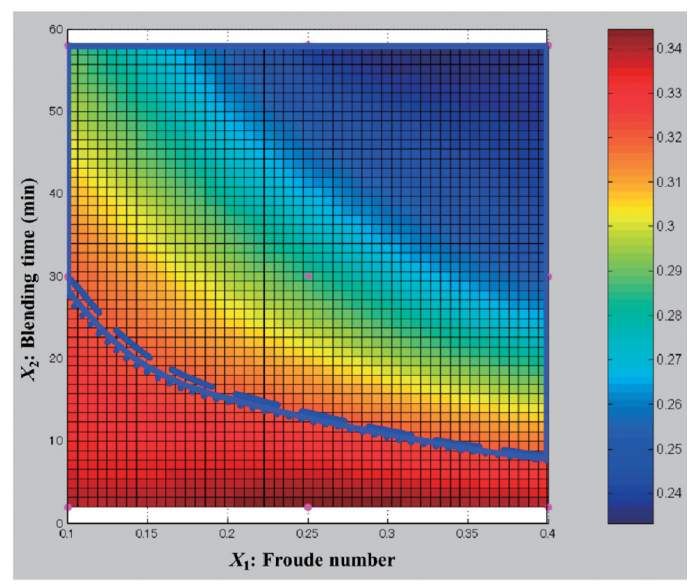

(b)

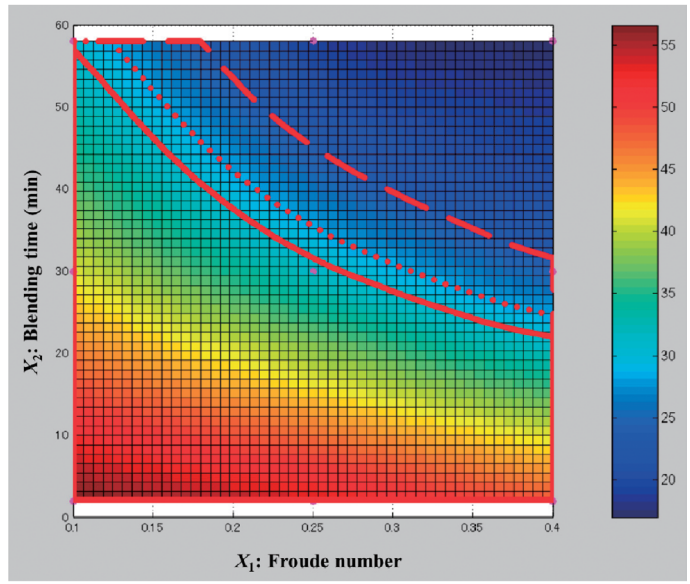

(c)

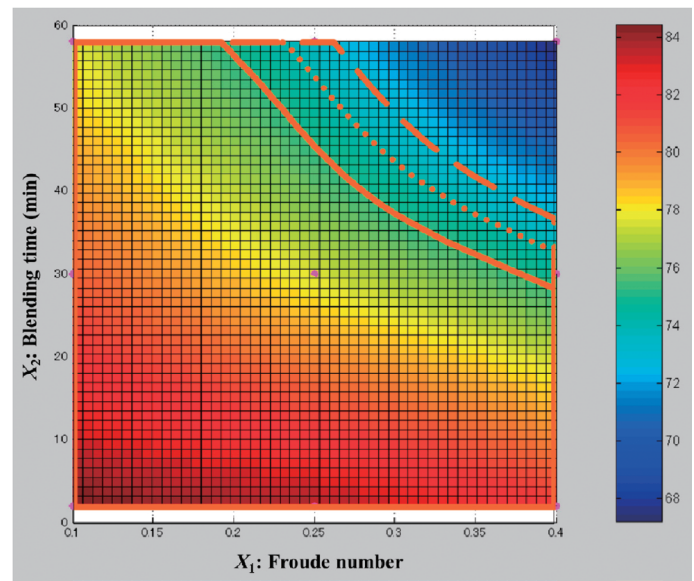

Fig. 6. Response Surfaces for the Quality Attributes on the Large Scale (a) Compression rate of powder mixture $\left(Y_{1}\right)$, (b) tablet hardness $\left(Y_{2}\right)$, and (c) dissolution rate at $30 \mathrm{~min}\left(Y_{3}\right)$. The dashed line represents the edge of the small-scale acceptance area, the dotted line represents the edge of the previously reported large-scale acceptance area, and the solid line represents the edge of the improved large-scale acceptance area. 
response surfaces at the three large-scale experimental conditions $\left(X_{\text {optimal }}, X_{\text {changed 1 }}\right.$, and $\left.X_{\text {changed } 2}\right)$. Standard deviations of the small-scale response surfaces under these three conditions were evaluated using the bootstrap resampling technique and SOM clustering (Table 5). Note that if a multiple linear regression analysis was applied as an RSM instead of an RSM-S, the standard error of the predicted value ${ }^{29)}$ could be regarded as the standard deviation of the prior probability.

Five batches of large-scale experiments were carried out under the three large-scale experimental conditions (three batches under $X_{\text {optimal }}$ and one batch each under $X_{\text {changed } 1}$ and $X_{\text {changed2). The experimental values on the large scale are }}$ also summarized in Table 5. The compression rates in the large-scale experiments were consistent with those in the small-scale response surfaces. This result indicated that there were no differences in the flowability of the powder between the manufacturing scales as long as the Froude number was kept constant. However, the large-scale experiments showed lower tablet hardness and dissolution rate values than the small-scale response surfaces. This finding indicated that the scale-up rule of the Froude number was not suitable for the predicting tablet hardness and dissolution rate because the powder was lubricated immediately when produced on the large scale. Standard deviations of the likelihood were estimated according to Eq. 9, from the maximum and minimum values of the three batches performed under the optimal conditions. Furthermore, considering small-scale prediction as the prior probability and large-scale data as the likelihood, we conducted Bayesian estimation using Eqs. 7 and 8 (Table
5). The Bayesian estimates of tablet hardness and dissolution rate were similar to the large-scale data because we considered the reliability of the scale-up rule and emphasized on the likelihood.

The least square method was performed to compute the correction coefficients of Eq. 10 between the quality attribute estimated from the small-scale response surface and the Bayesian estimate for the three process parameters. The results of a regression analysis are shown in Fig. 5. Squares of the correlation coefficients for all quality attributes were high $(\geq 0.98)$. The regression equation for the compression rate was nearly " $y=x$ " because compression rates on the small and large scales coincided. With regard to the hardness and dissolution rate, the primary regression coefficients were less than 1 , and the regression intercepts were negative, which indicated lower values on the large scale.

The large-scale response surfaces were then established by correcting all the small-scale response surfaces based on the calculated regression equations shown in Fig. 5. The corrected large-scale response surfaces are shown in Fig. 6. The acceptance area for the compression rate was unchanged. In contrast, the acceptance areas for the hardness and dissolution rate narrowed due to the scale-up because of the faster lubrication process. The large-scale acceptance areas calculated by Eqs. 7 and 8 were narrower than the previously-reported acceptance areas $^{25}$ calculated by Eqs. 5 and 6 because the small-scale knowledge was downplayed on the improved Bayesian estimation of quality attributes with discrepancy between the manufacturing scales. The acceptance areas were

Table 6. Validation Results of the Response Surfaces at the Edge of the Design Space

\begin{tabular}{|c|c|c|c|c|c|}
\hline Validation experiment number & 1 & 2 & 3 & RMSEP & Bias \\
\hline$X_{1}$ Froude number & 0.25 & 0.18 & 0.29 & & \\
\hline Rotation speed in V-10L (rpm) & 32 & 27 & 34 & & \\
\hline$X_{2}$ Time $(\min )$ & 32 & 16 & 11 & & \\
\hline \multicolumn{6}{|l|}{$Y_{1}$ Compression rate } \\
\hline Experiment data & 0.273 & 0.309 & 0.319 & & \\
\hline Predicted value from the small-scale $\mathrm{RS}^{a}$ ) & $\begin{array}{r}0.282 \\
(-0.009)^{b)}\end{array}$ & $\begin{array}{r}0.322 \\
(-0.013)\end{array}$ & $\begin{array}{r}0.322 \\
(-0.003)\end{array}$ & 0.009 & -0.008 \\
\hline Predicted value from the large-scale $\mathrm{RS}^{c}$ ) & $\begin{array}{r}0.278 \\
(-0.005)\end{array}$ & $\begin{array}{r}0.320 \\
(-0.011)\end{array}$ & $\begin{array}{r}0.320 \\
(-0.001)\end{array}$ & 0.007 & -0.006 \\
\hline $\begin{array}{l}\text { Predicted value from the improved } \\
\text { large-scale } \mathrm{RS}^{d)}\end{array}$ & $\begin{array}{r}0.280 \\
(-0.007)\end{array}$ & $\begin{array}{r}0.320 \\
(-0.011)\end{array}$ & $\begin{array}{r}0.320 \\
(-0.001)\end{array}$ & 0.008 & -0.006 \\
\hline \multicolumn{6}{|l|}{$Y_{2}$ Hardness $(\mathrm{N})$} \\
\hline Experiment data & 29.6 & 47.0 & 43.7 & & \\
\hline Predicted value from the small-scale $\mathrm{RS}^{a)}$ & $\begin{array}{c}37.9 \\
(-8.3)\end{array}$ & $\begin{array}{c}56.4 \\
(-9.4)\end{array}$ & $\begin{array}{c}55.7 \\
(-12.0)\end{array}$ & 10.0 & -9.9 \\
\hline Predicted value from the large-scale $\mathrm{RS}^{c}$ ) & $\begin{array}{c}32.2 \\
(-2.6)\end{array}$ & $\begin{array}{c}49.6 \\
(-2.6)\end{array}$ & $\begin{array}{c}48.9 \\
(-5.2)\end{array}$ & 3.7 & -3.5 \\
\hline $\begin{array}{l}\text { Predicted value from the improved } \\
\text { large-scale } \mathrm{RS}^{d)}\end{array}$ & $\begin{array}{c}29.7 \\
(-0.1)\end{array}$ & $\begin{array}{l}44.4 \\
(2.6)\end{array}$ & $\begin{array}{c}43.9 \\
(-0.2)\end{array}$ & 1.5 & 0.8 \\
\hline \multicolumn{6}{|l|}{$Y_{3}$ Dissolution rate at $30 \mathrm{~min}(\%)$} \\
\hline Experiment data & 74.5 & 83.9 & 82.4 & & \\
\hline Predicted value from the small-scale $\mathrm{RS}^{a}$ ) & $\begin{array}{c}80.6 \\
(-6.1)\end{array}$ & $\begin{array}{c}86.0 \\
(-2.1)\end{array}$ & $\begin{array}{c}85.9 \\
(-3.5)\end{array}$ & 4.2 & -3.9 \\
\hline Predicted value from the large-scale $\mathrm{RS}^{c}$ ) & $\begin{array}{c}78.6 \\
(-4.1)\end{array}$ & $\begin{array}{r}83.2 \\
(0.7)\end{array}$ & $\begin{array}{c}83.0 \\
(-0.6)\end{array}$ & 2.4 & -1.3 \\
\hline $\begin{array}{l}\text { Predicted value from the improved } \\
\text { large-scale } \mathrm{RS}^{d)}\end{array}$ & $\begin{array}{c}77.1 \\
(-2.6)\end{array}$ & $\begin{array}{l}81.2 \\
(2.7)\end{array}$ & $\begin{array}{l}81.1 \\
(1.3)\end{array}$ & 2.3 & 0.4 \\
\hline
\end{tabular}

a) RS: response surface. $b$ ) Error between actual and predicted value. $c$ ) Constructed by using Eqs. 5 and $6 . d$ ) Constructed by using Eqs. 7 and 8 . 
superposed to construct a large-scale design space (Fig. 7). The large-scale design space also narrowed as the Bayesian estimation improved.

Validation of the Response Surfaces We used three different conditions on the edge of the calculated large-scale design space for the validation experiments (Fig. 7). The results of these experiments for the response surfaces on the edge of the design space are summarized in Table 6. Regarding the compression rate for the powder mixture, all the response surfaces showed good and equivalent RMSEP and bias. This finding indicated that all the response surfaces had high estimation accuracy because no scale effect was involved. With regard to tablet hardness and dissolution rate, the renewed large-scale design space had higher prediction accuracy than the small-scale and previously-reported large-scale design spaces ${ }^{25)}$ because of the precise Bayesian estimation and correction of the discrepancy in the quality attributes between the manufacturing scales. We concluded that an accurate large-scale design space can be constructed by Bayesian estimation using the reliabilities of response surface models and scale-up rules without a large-scale DoE study, irrespective of the accuracy of the scale-up rule. Moreover, the good validation result indicated the adequacy of the number of large-scale experiments and the validity of the assumption that the standard deviation of the quality attribute was constant under any manufacturing condition.

\section{Conclusion}

A design space for the lubricant blending process for theophylline tablets was constructed on a large scale by using Bayesian estimation method based on the reliability of the scale-up rule. We confirmed that the corrected large-scale design space had higher prediction accuracy regardless of variation in the pharmaceutical quality between the manufacturing scales attributable to the improved Bayesian estimation.

Acknowledgements The authors are very grateful to Ms. Rie Saguchi (Daiichi Sankyo Co.) for her assistance with the experimental work.

\section{References}

1) ICH Guideline, "Pharmaceutical Development Q8 (R2)," August, 2009.

2) Huang J., Kaul G., Cai C. S., Chatlapalli R., Hernandez-Abad P., Ghosh K., Nagi A., Int. J. Pharm., 382, 23-32 (2009).

3) Lewis G. A., Mathieu D., Phan-Tan-Luu R., "Pharmaceutical Experimental Design," Marcel Dekker, New York, 1999.
4) Montgomery D. C., "Design and Analysis of Experiments," John Wiley \& Sons, U.S.A., 1997.

5) Aikhatib H. S., Sakr A., Pharm. Dev. Technol., 8, 87-96 (2003).

6) Huang Y. B., Tsai Y. H., Yang W. C., Chang J. S., Wu P. C., Biol. Pharm. Bull., 27, 1626-1629 (2004).

7) Marengo E., Cavalli R., Rovero G., Gasco M. R., Pharm. Dev. Technol., 8, 299-309 (2003).

8) Matsumura M., Nakagami H., Yamao T., Takayama K., Nagai T., Chem. Pharm. Bull., 42, 1902-1908 (1994).

9) Paterakis P. G., Korakianiti E. S., Dallas P. P., Rekkas D. M., Int. J. Pharm., 248, 51-60 (2002).

10) Rekhi G. S., Nellore R. V., Hussain A. S., Tillman L. G., Malinowski H. J., Augsburger L. L., J. Controlled Release, 59, 327-342 (1999).

11) Vojnovic D., Chicco D., El Zenary H., Int. J. Pharm., 145, 203-213 (1996).

12) Ogawa S., Kamijima T., Miyamoto Y., Miyajima M., Sato H., Takayama K., Nagai T., J. Pharm. Sci., 83, 439-443 (1994).

13) Takagaki K., Arai H., Takayama K., J. Pharm. Sci., 99, 4201-4214 (2010).

14) Takayama K., Morva A., Fujikawa M., Hattori Y., Obata Y., Nagai T., J. Controlled Release, 68, 175-186 (2000).

15) Takayama K., Obata Y., Morishita M., Nagai T., Pharmazie, 59, 392-395 (2004).

16) Arai H., Suzuki T., Kaseda C., Ohyama K., Takayama K., Chem. Pharm. Bull., 55, 586-593 (2007).

17) Arai H., Suzuki T., Kaseda C., Takayama K., Chem. Pharm. Bull., 57, 572-579 (2009).

18) Onuki Y., Ohyama K., Kaseda C., Arai H., Suzuki T., Takayama K., J. Pharm. Sci., 97, 331-339 (2008).

19) Arai H., Suzuki T., Yada S., Kaseda C., Onuki Y., Takayama K., Chem. Pharm. Bull., 59, 608-617 (2011).

20) Brone D., Alexander A., Muzzio F. J., AIChE J., 44, 271-278 (1988).

21) Horsthuis G. J. B., van Laarhoven J. A. H., van Rooij R. C. B. M., Vromans H., Int. J. Pharm., 92, 143-150 (1993).

22) Leuenberger H., Luy B., Studer J., STP Pharm. Sci., 6, 303-309 (1990).

23) ICH Quality Implementation Working Group, "Points to Consider ICH-Endorsed Guide for ICH Q8/Q9/Q10 Implementation,” December, 2011.

24) Peterson J. J., J. Biopharm. Stat., 18, 959-975 (2008).

25) Maeda J., Suzuki T., Takayama K., Drug Dev. Ind. Pharm., in press.

26) Carr R. L., Chem. Eng., 72, 163-168 (1965).

27) Lindley D. V., "Introduction to Probability and Statistics from a Bayesian Viewpoint, Part 2. Inference," Cambridge University Press, Cambridge, 1965.

28) ISTM International, "Manual on Presentation of Data and Control Chart Analysis," 8th Edition, America, 2010.

29) Samprit C., Ali S. H., "Regression Analysis by Example," 4th ed., John Wiley \& Sons, U.S.A., 2006. 